\title{
Quem somos? O perfil educacional do formado em Jomalismo na UFMA de Imperatriz (MA)
}

\author{
Marco Antônio Gehlen? \\ Thaísa Bueno² \\ Vanessa de Paula3
}

\begin{abstract}
Resumo: Considerando que o curso de Jornalismo da Universidade Federal do Maranhão, campus de Imperatriz, completou dez anos em 2016 e está implementando uma nova grade curricular para atender as novas exigências do Ministério da Educação, bem como a ausência de levantamentos sobre o perfil dos profissionais formados na instituição, este estudo objetivou traçar o perfil do formado em Jornalismo de Imperatriz, levantando o que esses pensam acerca de sua formação. Para tanto, desenvolveu-se uma investigação com método quantitativo-descritivo para levantamento e análise de dados a partir da aplicação de um questionário semiestruturado por meio do qual foi possível obter respostas de $88,6 \%$ dos formados pretendidos. Tem-se que apenas 176 graduandos se formaram nos dez primeiros anos do curso, uma vez que 520 alunos deveriam ter alcançado a formação até o período 2015.2. permite compreender informações adicionais sobre perfil dos formados com pistas para os novos rumos do curso.
\end{abstract}

Palavras-chave: Graduação em Jornalismo. Perfil discente. UFMA. Imperatriz. Redes Sociais.

Abstract: Considering that the Journalism course of the Federal University of Maranhão, Imperatriz campus, completed ten years in 2016 an dis implementing a new curriculum tome et the new requirements of the Ministry of Education, as well as the absence of survey son the profile of trained professionals In the institution, this study aimed to trace the profile of the graduated in Imperatriz Journalism, raising what they think about their formation. For that, a quantitative-descriptive method was developed for data collection and analysis through the application of a semi-structured questionnaire through which it was possible too brain responses of $88.6 \%$ of the intended forms. It is estimated that only 176 graduates graduated in the first ten years of the course, since 520 students were expected to have completed their training until 2015. The article all susto understand additional profile information of trainees with clues to the new course directions.

Keywords: Graduation in Journalism. Student profile. UFMA. Imperatriz.

Resumen Considerando que el curso de Periodismo de la Universidad Federal de Maranhão, campus de Imperatriz, cumplió diez años en 2016 y está implementando una nueva parrilla curricular para atender las nuevas exigencias del Ministerio de Educación, así como la ausencia de levantamientos sobre 
el perfil de los profesionales formados en la institución, este estudio objetivo trazar el perfil del formado en Periodismo de Imperatriz, levantando lo que estos piensan acerca de su formación. Para ello, se desarrolló una investigación con método cuantitativo-descriptivo para levantamiento y análisis de datos a partir de la aplicación de un cuestionario semiestructurado por medio del cual fue posible obtener respuestas del $88,6 \%$ de los formados pretendidos. Se tiene que sólo 176 graduados se formaron en los diez primeros años del curso, ya que 520 alumnos deberían haber alcanzado la formación hasta el período 2015.2. El artículo permite comprender in formación adicional sobre perfil de los formados con pistas para los nuevos rumbos del curso.

Palabras clave: Graduación en Periodismo. Perfil de estudiante. UFMA. Imperatriz.

\section{Introdução}

O curso de Jornalismo da Universidade Federal do Maranhão, campus de Imperatriz, completou dez anos em 2016 e desde então não houve nenhum levantamento que traçasse o perfil dos profissionais formados na instituição. Não há registros na Coordenação do Curso, nos trabalhos de grupos de pesquisa ou trabalhos de conclusão que versem sobre essa problemática. Então, inicialmente, o estudo será um primeiro registro histórico. Some-se a isso o fato de que em 2016 o curso começou a pensar uma nova grade curricular para atender as novas exigências do Ministério da Educação, que instituiu as Novas Diretrizes Curriculares Nacionais para o curso de graduação em Jornalismo, de modo que possuir essas informações permite reavaliação das escolhas do curso, bem como pode guiar ações futuras.

Fora isso, levantamento de perfis são ferramentas bastante comuns quando se pensa em estudos educacionais e profissionais. Entre os comumente encontrados, há exemplos como os estudos que traçam o perfil de alunos de instituições de Educação a Distância (EAD), Educação de Jovens e Adultos (EJA) e mesmo egressos de cursos de graduação de instituições públicas e particulares. Além disso, também são feitos perfis de profissões. A Federação Nacional dos Jornalistas (Fenaj), por exemplo, divulgou em 2013 uma pesquisa que identificou o perfil dos jornalistas do Brasil; outros órgãos nacionais e internacionais também têm essa prática. Entre eles, pode-se citar o Fórum Nacional de Professores de Jornalismo (FNPJ) e a Associação Brasileira de Pesquisadores em Jornalismo.

Neste sentido, a presente pesquisa buscou entender quem é o formado em Jornalismo de Imperatriz e o que pensa acerca de sua formação. Dessa maneira, pode vir a servir como ponto de partida para abrir o campo de visão para outras questões relacionadas ao curso, ao estudante ou ao profissional. Afinal, conhecer essa realidade é uma forma de trilhar caminhos mais precisos. Sercundes, Levay \& Moraes (2014) afirmam que um bom planejamento, abrangendo fatores como o perfil, apresenta-se como uma importante estratégia para instituições pensarem práticas e planejarem trabalhos. "O planejamento configura-se como catalisador para o sucesso dos cursos" (Sercundes, Levay \& Moraes, 2014, p. 8).

Na atualidade, de acordo com levantamento publicado pela Folha de S. Paulo em 2016 - "Ranking Universitário da Folha" - no Brasil, 315 instituições oferecem o curso de Comunicação Social-Habilitação em Jornalismo no Brasil. Dessas, 275 são particulares e 40 são públicas. No Maranhão são três instituições autorizadas: a UFMA (São Luís e Imperatriz), 
Faculdade de Ciências Humanas e Sociais Aplicadas (FAC São Luís) e Instituto Maranhense de Ensino e Cultura (Imec). No Estado, além de São Luís, que é a Capital e oferece a habilitação tanto nas universidades públicas quanto nas faculdades privadas, apenas o município de Imperatriz oferta o curso, na UFMA. Pelo ranking que cataloga os melhores e os piores cursos do país, o curso da UFMA ocupa a 52ª posição. Apesar da colocação longínqua, está bastante a frente das concorrentes particulares, ranqueadas em 176 e 294, respectivamente.

E por que é importante obter informações sobre os graduados do curso de Imperatriz? Bem, em dez anos de existência do curso de Jornalismo, apenas 176 graduandos se formaram, uma vez que 520 alunos deveriam ter alcançado a formação até o período 2015.2 É notável também que, com determinada frequência, os egressos de cursos de ensino superior não desenvolvem atividades relacionadas a sua área de formação. Inclusive essa é uma questão nessa pesquisa. Portanto, com o intuito de conhecer os atores das mudanças mencionadas e suas trajetórias, este trabalho se propõe a identificar o perfil dos egressos sob os aspectos socioeconômicos e educacionais, concentrando foco nos formados no período de 2010.2 a 2015.2 - tendo a primeira turma ingressado em 2006 -, exatos dez anos desde a implantação do curso na cidade.

Assim, para entender o surgimento e desenvolvimento do ensino de Jornalismo em nosso país e até poder olhar de maneira crítica para a realidade no Maranhão e, particularmente em Imperatriz, faz-se pertinente conhecer o processo de formação. Optou-se, portanto, por utilizar o método quantitativo-descritivo para levantamento e análise de dados. O instrumento de coleta de dados utilizado foi um questionário semiestruturado online na plataforma dos Formulários do Google, por meio do qual foi possível obter respostas de $88,6 \%$ dos formados pretendidos.

\section{Jornalismo em Imperatriz}

Situada numa área de 1.376 quilômetros quadrados, Imperatriz é considerada segunda maior cidade do Estado e a maior cidade do sul do Maranhão, ocupando um ponto central na microrregião conhecida com Bico do Papagaio, que abrange 66 municípios (25 no Pará, 25 no Tocantins e 16 no Maranhão) numa área total de 140 mil km² e cuja população chega a 1,6 milhões de habitantes, conforme o último Censo (2010). Desde quando foi implantado, em 2006, até hoje (dez anos depois), o curso de bacharelado em Comunicação Social - hoje em Jornalismo - é o único da cidade e, de certa forma, da região, uma vez que outra graduação nessa área só pode ser encontrada a cerca de 600 quilômetros de distância - São Luís (MA), Palmas (TO) ou Belém (PA) - e nenhuma outra habilitação é ofertada também nos arredores.

Pela peculiaridade regional, marcada pela ausência de formação especializada nesse campo do conhecimento, não é de se estranhar que o curso tenha sido selecionado para integrar as ofertas da Universidade Federal do Maranhão. Atendendo a um anseio da sociedade e dos profissionais da região, foi publicada em 2005 a resolução número 83/2005 do CONSUN, que autorizava a criação do curso como parte do programa de Expansão Universitária do Ministério da Educação. O curso autorizado, presencial e vespertino, teve seu reconhecimento efetivado na Portaria SESU/MEC nº 479 de 25/11/2011. Em 2014 na sua revalidação, contabilizou os conceitos 4 (ENADE) E 3 (CURSO). A primeira turma em 2007, foi composta por 40 alunos e hoje o curso possui 176 formados. 


\section{A formação: perfil do egresso}

Esta pesquisa buscou traçar o perfil do egresso do curso de Jornalismo da Universidade Federal do Maranhão acerca dos aspectos socioeconômicos e educacionais. Para tanto, foi feito um levantamento de dados junto à Coordenação do Curso de Jornalismo desta instituição para obter-se dados oficiais de ingressantes e concluintes desde a primeira turma do curso no segundo semestre de 2006 até a última concluinte no recorte de uma década, em $2015^{4}$ Foram investigados os egressos que entraram no segundo semestre de 2006 até aqueles que ingressaram no primeiro semestre de 2012. Ao todo, 12 turmas foram consultadas. Com esses dados foi possível verificar a quantidade de alunos formados no curso ao longo de dez anos.

O estudo utilizou a metodologia quantitativa survey descritiva, cujo intento é "identificar quais situações, eventos, atitudes ou opiniões estão manifestos em uma população" (Freitas, Oliveira, Saccol \& Moscarola, 2000, p. 3). O instrumento de coleta de dados empregado foi um questionário online com questões objetivas. Quanto ao número de momentos ou pontos no tempo em que os dados são coletados, foi feito um corte-transversal (cross-sectional) que, segundo os autores, "ocorre em um só momento, pretendendo descrever e analisar o estado de uma ou várias variáveis em um dado momento" (Freitas, Oliveira, Saccol \& Moscarola, 2000, p. 3). Esse modelo atende o objetivo desta pesquisa, pois o corte foi feito no período de uma década, a fim de analisar as variáveis desse dado momento.

Deste modo, a presente pesquisa é resultado da análise das respostas de um questionário online aplicado entre os dias 19 de julho de 2016 e 05 de agosto de 2016, por meio de uma ferramenta do Google Formulários. De acordo com os dados do SIGAA (Sistema Integrado de Gestão de Atividades Acadêmicas), de 2010 (ano da primeira turma de formados) até o segundo semestre de 2015, 176 estudantes concluíram o curso de Comunicação Social com habilitação em Jornalismo da Universidade Federal do Maranhão, Campus de Imperatriz. Desses, 154 responderam ao questionário. O recorte permite dizer que se trata de um perfil efetivo do formado no curso porque contemplou $88,6 \%$ dos egressos e garante uma margem de erro de $3 \%$ para mais ou para menos, conforme recurso que serviu de base.

Quanto a amostragem, a presente pesquisa é classificada como probabilística pois, embora não tenha seguido a característica de "todos os elementos da população terem a mesma chance de ser escolhidos" (Freitas, Oliveira, Saccol \& Moscarola, 2000, p. 4) - uma vez que os membros da amostra não foram escolhidos por sorteio - o questionário foi enviado para quase $100 \%$ dos formados, no entanto, 88,6\% disponibilizaram a responder. Apesar disso, como a porcentagem é alta e o universo é finito, é possível realizar inferências sobre toda a população observada, ou seja, os resultados são generalizáveis.

\section{Aspectos socioeconômicos}

A primeira premissa norteadora dessa pesquisa propôs-se a analisar o gênero, a faixa etária, a cor/raça, o estado civil, renda dos formados, a naturalidade e local que mora atualmente, a fim de descobrir se a universidade tem realizado o que se propõe a fazer. ser um local de 
democracia e inclusão social. Quanto à naturalidade, a pesquisa revelou que a maioria dos graduados são maranhenses como mostra a Figura 1. No entanto, a universidade atende à demanda dos estados vizinhos, sendo dez dos graduados naturais do estado do Pará, o que corresponde a 6,8\% da amostra. Os estados Piauí e Tocantins também aparecem na amostra, com quatro graduados naturais de cada um desses Estados. Além do mais, existe um graduado natural de cada um dos estados de Goiás, Brasília, Espírito Santo, Rio de Janeiro Paraná, Paraíba, Mato Grosso e Rio Grande no Norte.

De fato, o curso, tem atendido a demanda da cidade, uma vez que era um anseio da sociedade imperatrizense quando foi implantado na UFMA, como mencionado nos capítulos anteriores. Mas mais que isso, a universidade tem atendido, além da demanda do Maranhão aos estados fronteiriços: Pará, Piauí e Tocantins. Como Imperatriz está localizada próxima à microrregião do Bico do Papagaio, ao acolher esses estudantes ratifica seu potencial aglutinador em relação às outras regiões e confere ao curso uma natureza integradora. Quanto às pessoas de estados das regiões Sul, Sudeste e Centro-Oeste, descobriu-se no levantamento que se trata de cidadãos que já moravam na cidade antes de ingressar no curso, sendo efetivamente um curso regional. É importante mencionar que, conforme as Novas Diretrizes Curriculares Nacionais para o Curso de Jornalismo (2013), disciplinas de cunho regional devem ser incluídas no currículo.

Gráfico 1 - Naturalidade do aluno formado no curso de Jornalismo da UFMA

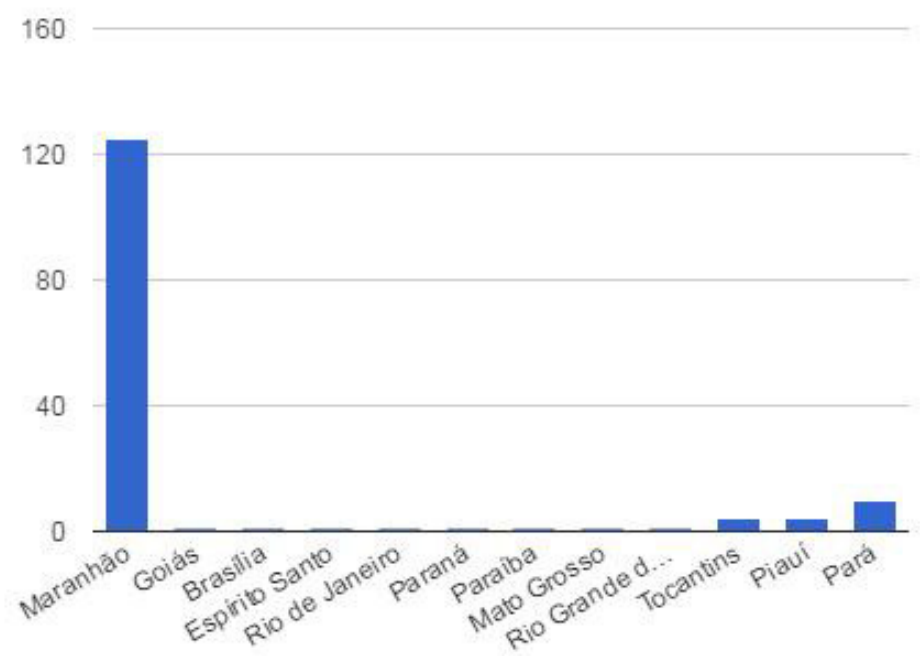

Fonte: Os autores (2016)

Quanto ao gênero, a análise revela que 68,6\% dos graduados são mulheres, conforma a Figura 2. É interessante mencionar que na pesquisa de Morais (2010) sobre "O perfil do jornalista em Imperatriz nas emissoras de televisão, rádio e jornal impresso", 81 \% dos cargos da atividade jornalística eram ocupados por homens. Embora a presente análise trate do perfi de graduados, e não especificamente de jornalistas em exercício, é importante observar uma grande quantidade de mulheres formadas em Jornalismo e que isso, possivelmente represente uma maior presença feminina no exercício da profissão dentro das redações, assessorias, etc. da cidade numa possível atualização do estudo desenvolvido pelo pesquisador em 2010. Esse dado, inclusive, está em conformidade com a investigação nacional realizada pela Fenaj, "Perfil profissional do jornalismo, brasileiro", que traçou a representação do profissiona 
jornalista ao final de 2012, segundo a qual 64\% da amostra era formada por mulheres. Embora o estudo seja de 2012 (publicado em 2013) é o levantamento mais atual da entidade.

Gráfico 2 - Gênero do aluno formado no curso de Jornalismo da UFMA

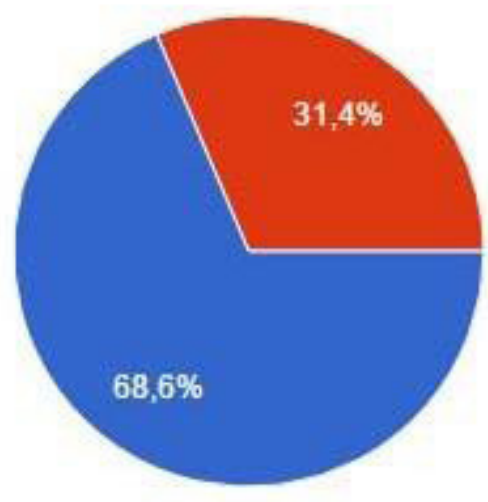

Feminino

Masculino

Outros

Fonte: Os autores (2016)

O resultado do questionário também revela que a maioria dos formados em Imperatriz são jovens com idade entre 21 e 30 anos como é possível observar na Figura 3. Conforme pode-se levantar, 54,5\% têm idade entre 26 a 30 anos; e 30,8\% têm entre 21 e 25 anos. Essa é outra diferença em relação ao perfil do jornalista de Imperatriz em 2010. A metade dos entrevistados tinham entre 36 e 50 anos. Apenas 19\% eram jovens de 18 a 25 anos. Isso pode representar uma possibilidade de renovação da atividade dentro da cidade, pois quanto mais jovens formados, mais chances de o quadro de jornalistas se renovar e a prática se despedir dos velhos vícios da profissão. Além disso, esse dado pode revelar que os estudantes interessados neste curso são aqueles recém-saídos do Ensino Médio e, além do mais, o turno vespertino pode não atrair pessoas de mais idade, já empregadas no horário comercial de trabalho.

Gráfico 3 - Faixa etária do aluno formado no curso de Jornalismo da UFMA

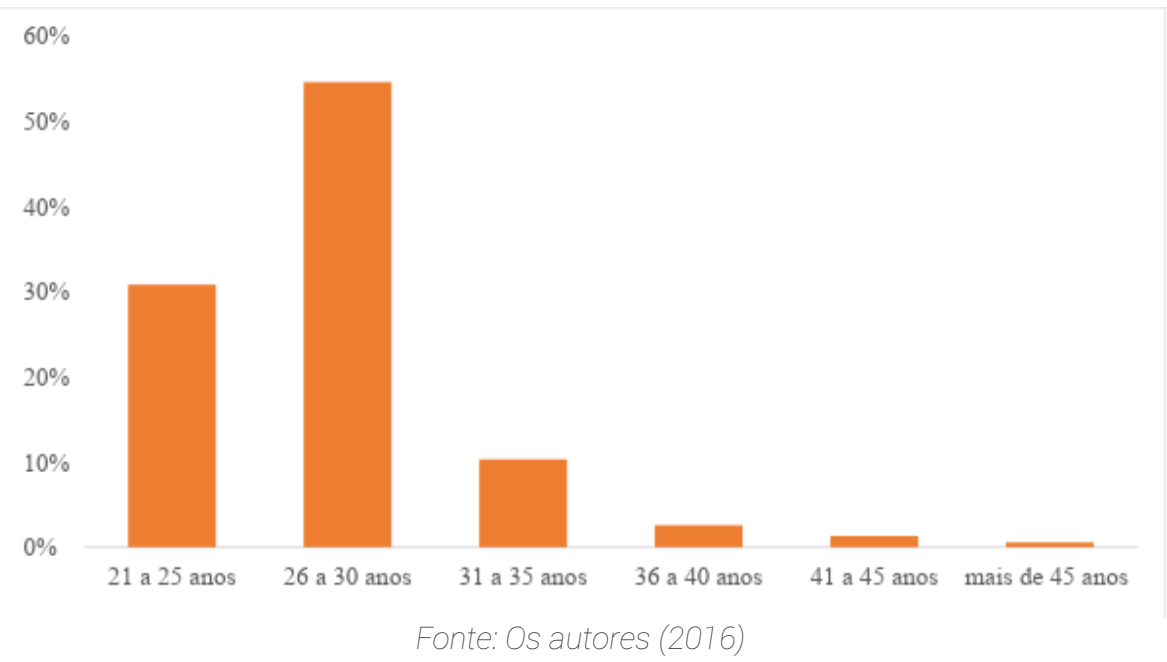

Quanto à cor/raça, 47,4\% dos formados consultados se autodeclararam pardos e 26,3\% se autodeclararam pretos, como demostra a Figura 4. Esse é um ponto positivo, pois é pos- 
sível observar a diversidade racial que a universidade tem alcançado. No entanto, a partir da observação dessa amostragem foi possível perceber a inexistência de estudantes autodeclarados índios ${ }^{5}$. De acordo com dados da Fundação Nacional dos Índios (Funai), cerca de 600 índios residem na região:

Os Krikati, cujo nome significa "aldeia grande" autodenominam-se Krikateré. Habitam um território, recentemente demarcado e não homologado com 146.000 hectares localizados no município de Montes Altos, Amarante, Sítio Novo e Lajeado Novo. São cerca de 600 índios que, atualmente estão divididos em duas aldeias, situada às margens da rodovia MA 280 (Almeida, 2016, página única)

Esta pesquisa, embora não tenha o objetivo de se aprofundar nessas questões, sugere o seguinte questionamento acerca dessa questão: por que o curso não tem atraído a população indígena ou por que pessoas autodeclaradas indígenas não concluíram o curso?

\section{Gráfico 4 - Cor/raça do aluno formado no curso de Jornalismo da UFMA}

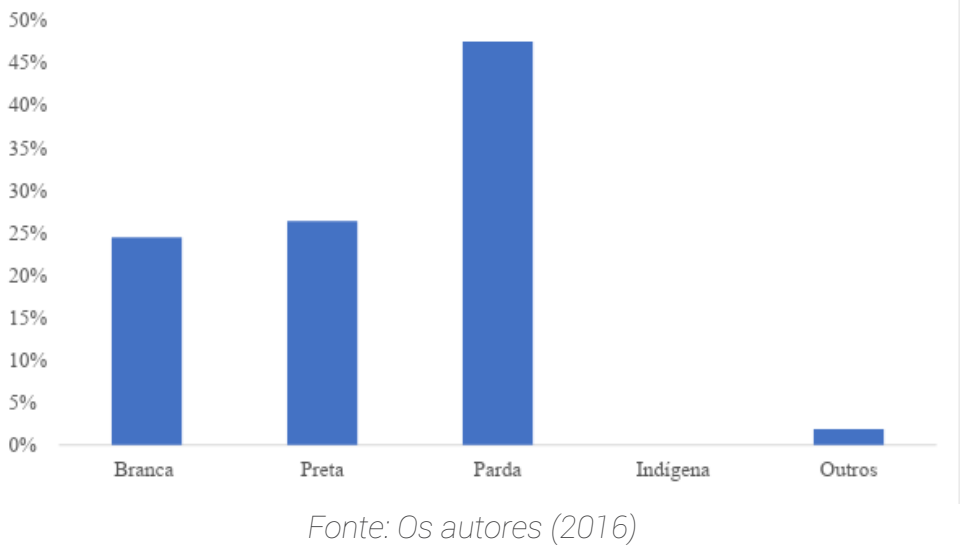

O estado civil foi outro ponto levantado nesse estudo. A partir das respostas, verificamos que 122 dos graduados são solteiros, representando 76,2\% da amostra. Os casados são 32 e representam 20,5\% e os divorciados são duas pessoas (1,3\%) como é possível observar na Figura 5.

Gráfico 5 - Estado civil do aluno formado no curso de Jornalismo da UFMA

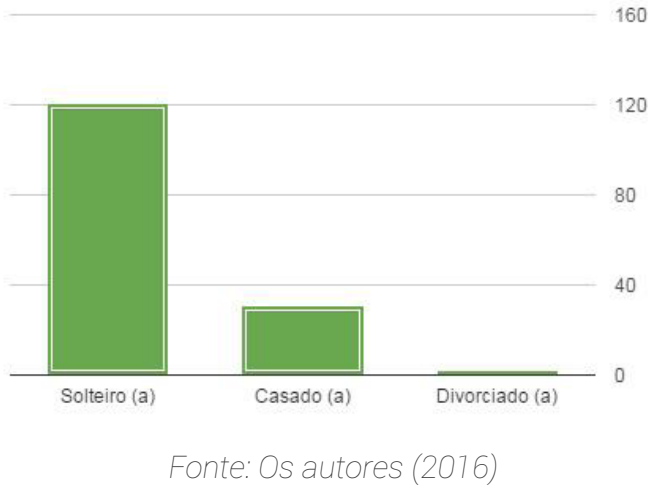

${ }^{5}$ No entanto, a avó de um egresso é indígena, porém, nos documentos do egresso constam como pardo e não indígena. 
Constatou-se, ainda, que 57 dos consultados possuem remuneração de até dois salários mínimos, o que representa 36,5\% da amostra. Enquanto 35 recebem de dois a três salários mínimos, representando 22,4\% da amostra. Além disso, 14 pessoas, que representam 9\% da amostra responderam que não possuem atividade remunerada no momento, como mostra a Figura 6. É importante mencionar que se trata da renda mensal individual, o que significa que a maioria dos graduados estão no mercado de trabalho, seja dentro da área de comunicação ou fora.

É preciso ponderar que o parâmetro utilizado para quantificar o salário dos consultados foi o salário mínimo (R\$ 880,00), uma vez que nem todos os egressos atuam como jornalistas. No entanto, conforme o Sindicato dos Radialistas do Maranhão (SINRAD-MA), o piso salarial dos jornalistas do Maranhão vigente até dia 30 de junho de 2017 é de R\$2.490,03 para produção e de R\$ 1.871,87 para técnica. O resultado mostra que 46,8\% recebe abaixo do piso salarial do Estado, enquanto 44,2\% recebem dentro do piso. Entretanto, deve-se lembrar que parte dos consultados realizam mais de uma atividade remunerada.

Gráfico 6 - Remuneração do aluno formado no curso de Jornalismo da UFMA

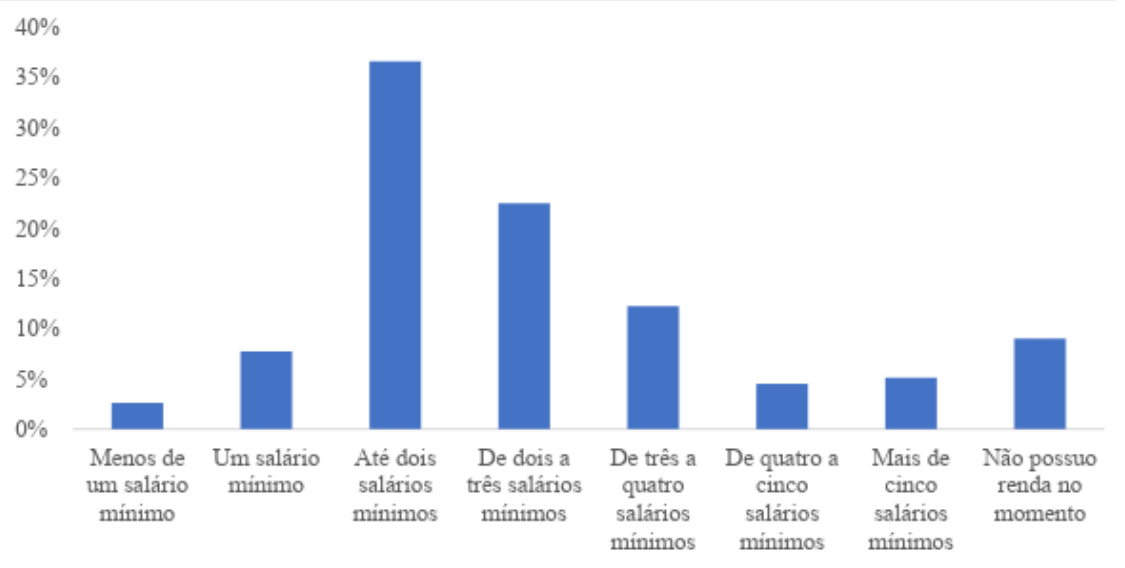

Fonte: Os autores (2016)

A última questão relacionada à categoria socioeconômica tratou de investigar sobre o local onde o estudante reside atualmente. A maioria dos consultados moram em Imperatriz, apenas 30,1\% moram em outras cidades, conforme mostra a Figura 7.

Gráfico 7 - Cidade atual do aluno formado no curso de Jornalismo da UFMA

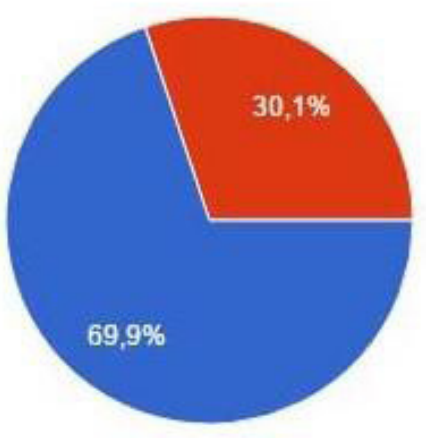

Imperatriz - Maranhão

Outros

Fonte: Os autores (2016) 
A partir da exposição desses dados, é possível perceber que o formado reúne homens e mulheres, jovens, a maioria solteiro, com diversidade racial e remuneração dentro do piso salarial do Estado e poucos estão desempregados. Além disso, a maioria é natural do Maranhão e que mora em Imperatriz.

\section{Aspectos Educacionais}

Essa parte da pesquisa pretendeu verificar quais as oportunidades que a formação em Jornalismo proporcionou ou, ainda, se o egresso continua buscando capacitação, seja em outros cursos em especializações ou em outro curso de ensino superior. Embora não tenha verificado a relação direta entre a formação em Jornalismo e as atividades posteriores a esta, acredita-se que é importante ter um registro das possibilidades e caminhos traçados pelos alunos egressos.

Além disso, pretendeu-se verificar quantos estudantes participaram de atividades de pesquisa e extensão enquanto estavam na universidade, além de observar quais motivos os impossibilitaram ou instigaram a participar. Buscou-se também saber o grau de satisfação quanto à formação em Jornalismo, além de questionar o que faltou na formação, conforme a opinião do egresso.

Quanto à forma de ingresso dos formados, verificou-se que aqueles que entraram pela ampla concorrência representam 68,9\% dos formados, enquanto os cotistas representam 30,1\%, como mostra a Figura 8. Os que responderam "Outros" foram duas pessoas (1,3\%): um informou que ingressou por Processo seletivo gradual e o outro por Cotas para Deficientes Físicos.

Acredita-se que esta é uma boa porcentagem para os alunos cotistas, embora atualmente mais da metade das vagas (52\%) sejam reservadas para cotistas. Isso significa que ainda existe uma quantidade significativa de cotista que não concluiu o curso. Embora não tenha sido uma preocupação desta pesquisa, a partir destes dados é possível questionar por que quase metade dos cotistas não chega a concluir o curso e o que é possível fazer para diminuir a evasão.

Gráfico 8 - Forma de ingresso na universidade

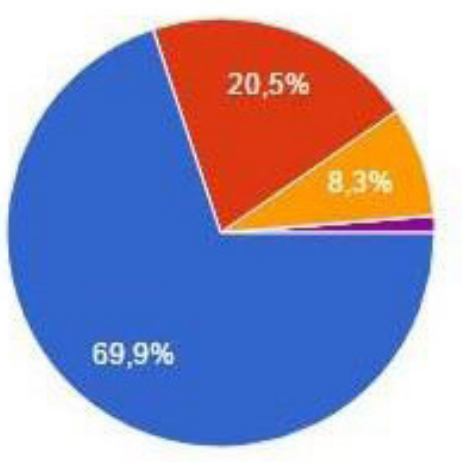

Ampla concorrência

Cotas para escolas públicas

Cotas para negros

Cotas indigenas

- Outros

Fonte: Os autores (2016)

É importante mencionar que o Sistema de Seleção Unificada (Sisu) foi utilizado como forma única de ingresso na Universidade Federal do Maranhão - Imperatriz desde de 2009 Partindo dessa informação, percebeu-se que a taxa de alunos que não concluíram o curso a 
partir de 2010 foi maior em comparação com os alunos que ingressaram de 2006 a 2008. 0 Quadro 7ilustra a quantidade de formados de cada turma até o segundo semestre de 2015. Na primeira coluna consta o ano e semestre de ingresso e na segundo coluna a quantidade de estudantes que ingressaram no período respectivo até o segundo semestre de 2015.

Quadro 1 - Quantidade de formados até 2015.2 e respectivo ano/período de ingresso

\begin{tabular}{|c|c|}
\hline Ano/Período de ingresso & Quantidade de alunos formados até 2015.2 \\
\hline 2006.2 & 15 formados \\
\hline 2007.1 & 23 formados \\
\hline 2007.2 & 24 formados \\
\hline 2008.1 & 20 formados \\
\hline 2008.2 & 21 formados \\
\hline 2009.1 & 19 formados \\
\hline 2009.2 & 14 formados \\
\hline 2010.1 & 12 formados \\
\hline 2010.2 & 6 formados \\
\hline 2011.1 & 4 formados \\
\hline 2011.2 & 8 formados \\
\hline 2012.1 & 9 formados \\
\hline & \\
\hline
\end{tabular}

Fonte: Os autores(2016)

Da turma que ingressou em 2006.2, 15 formaram até o segundo semestre de 2015. 0 último formado dessa turma concluiu o curso no segundo semestre de 2013. Já dos que ingressaram em 2007.1, 23 concluíram o curso. O último dessa turma concluiu no segundo semestre de 2012. Dos que ingressaram em 2007.2, 24 formaram e o último da turma a concluir foi no segundo semestre de 2014. Da turma de 2008.1, 20 finalizaram o curso e o último aluno formou-se no primeiro semestre de 2015. Da turma de 2008.2 foram 21 formados e o último concluiu no segundo semestre de 2015.

As turmas seguintes ingressaram pelo Sistema de Seleção Unificada (Sisu), como já mencionado. É visível o crescente número de alunos evadidos. No entanto, percebeu-se que grande parte dos formados levou mais de quatros anos para concluir a formação. Dessa forma acredita-se que, embora haja poucos formados dessas turmas, o número de egressos que ingressaram a partir de 2011 ainda pode aumentar, caso os estudantes dessas turmas permaneçam no curso. Entretanto, a presente pesquisa não se preocupou em verificar quantos dos estudantes encontram-se atrasados em relação ao ano de conclusão do curso.

Foi perguntando também se o egresso havia concluído outro curso superior antes de cursar Jornalismo. A maioria (92,9\%) não concluiu como mostra a Figura 9, mas 11\% fizeram cursos como: Biologia, Letras, Pedagogia, Administração, História e Geografia. Isso confirma a premissa de que a maioria dos ingressantes do curso são alunos recém-saídos do Ensino Médio. 


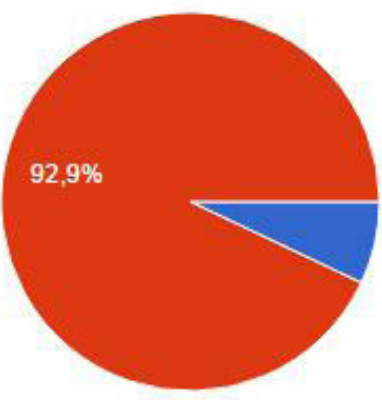

Fonte: Os autores (2016)

Ademais, a pesquisa consultou quantos haviam feito outro curso superior enquanto cursavam Jornalismo. A maioria não fez, mas 16 pessoas cursaram, o que representa 17,6\% da amostra, conforme apresenta a Figura 10. Os cursos foram: Letras, História, Administração, Pedagogia, Serviço Social e Geografia. Isso pode ser explicado pelo fato de que até o ano de 2009 era permitido ocupar duas vagas simultaneamente no curso de ensino superior em instituições públicas. Entretanto, isso não foi mais possível a partir da publicação da a Lei no 12.089 de 11 de novembro de 2009. Além desse fato, há estudantes que se instruem simultaneamente em instituição pública e particular.

\section{Gráfico 10 - Formação superior simultânea a Jornalismo}

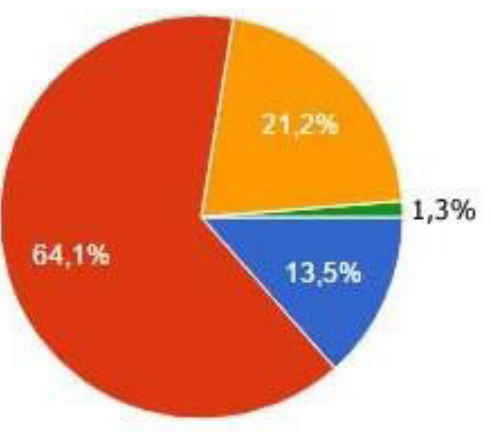

Fonte: Os autores (2016)

Quanto à motivação para escolher Jornalismo, a maioria $(87,2 \%)$ respondeu que esse era o curso que queria, enquanto 12,8\% responderam que não conseguiram nota suficiente para ingressar em outro curso, como exposto na Figura 11. É importante observar que esse dado de fato, não surpreende, pois se os egressos finalizaram o curso é porque, de fato, gostavam do que estudavam. 


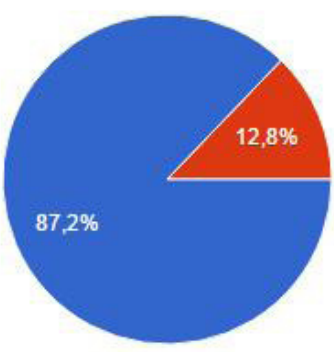

Porque queria esse curso mesmo

Porque não passou em outro.

Fonte: Os autores (2016)

Por entender que a participação em projetos de pesquisa é importante, esta pesquisa quis saber, ainda, quantos participaram de projeto de pesquisa na universidade. Os resultados dessa amostra, no entanto, apontam que pouco mais da metade não participou (56,4\%), enquanto $43,6 \%$ participaram, assim demonstra a Figura 12. Os que não participaram informaram motivos como: falta de tempo, falta de oportunidade, falta de interesse, falta de incentivo e divulgação e poucos projetos de pesquisa na época. Até 2015 só havia um grupo de pesquisa. Atualmente existem oito grupos de pesquisa

\section{Gráfico 12 - Participação em projeto de pesquisa}

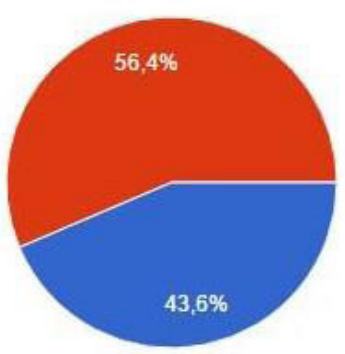

\section{- Sim}

- Não

Fonte: Os autores (2016)

No que se refere a projetos de extensão, a maioria não participou $(68,9 \%)$ enquanto 31,1\% participou, como expõe a Figura 13. Entre os motivos de não ter participado de atividades de extensão, as respostas foram: falta de tempo, falta de oportunidade, falta de interesse, sobrecarga de atividades, falta de incentivo e divulgação, porque trabalhava, priorizou a pesquisa e porque tinha foco no mercado.

Gráfico 13 - Participação em projeto de extensão

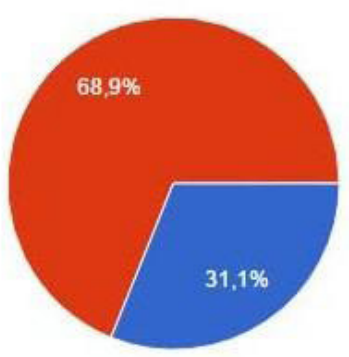


Em relação à satisfação quanto a formação em Jornalismo, 13,5\% dos consultados se mostram muito satisfeitos, 64,1\% se dizem satisfeitos, mas 21,2\% responderam que se consideram insatisfeitos, como pode-se observar na Figura 14. Em busca de aprofundar a investigação neste quesito, foi perguntado o que faltou na formação. As respostas mais comuns foram relacionadas à prática em laboratórios, principalmente de rádio, de TV e na prática em estágio. Entretanto, outras respostas surgiram como: disciplinas de história, aprofundamento teórico, incentivo à pesquisa e extensão, disciplinas de empreendedorismo e marketing e disciplinas de inglês. Destacam-se algumas respostas para a pergunta "O que você acha que faltou em sua formação de jornalista?".

Mais relação da minha graduação com a sociedade e uma vinculação maior com aspectos comunicativos da América Latina. (Egresso 1). ${ }^{6}$

Formação prática. A universidade não pode focar apenas na pesquisa e extensão e esquecer da formação prática para a rotina no mercado. 0 estudante precisa sair com a bagagem teórica, mas também prática (Egresso 2)

Matérias menos mecanizadas do que é o fazer jornalístico (Egresso 3)

Uma dose de realidade. Nosso curso não prepara os alunos para a realidade do mercado de trabalho. Quando falamos na realidade imperatrizense, o problema é ainda mais grave. Nosso mercado não possui cultura de boa remuneração e exige profissionais polivalentes (com diversas habilidades). Muitos - se não a maioria - dos acadêmicos saem da universidade com uma área de identificação e o restante, com um conhecimento muito raso (Egresso 4). Técnicas para jornalismo investigativo. Acho fascinante, mas não tivemos nada sobre isso no curso [...] (Egresso 5)

Senti falta de uma formação mais crítica, humanista (Egresso 6).

Faltou mais preparo profissional no estágio, para nos capacitar enquanto alunos para um futuro mercado de trabalho. E mais estrutura para as disciplinas específicas, principalmente em Telejornalismo (Egresso 7).

A partir dessas respostas foi possível verificar que a maioria dos insatisfeitos fizeram parte das primeiras turmas e as razões de suas insatisfações se resumem a falta de laboratórios de professores, de estágio, e, os que estagiaram no início informaram que haviam poucas opções. Atualmente a realidade é diferente, embora se saiba que há muito para evoluir, a adoção de uma nova grade poderá vir a sanar essas lacunas já que busca equilibrar áreas de interesse (humanidades, teorias e laboratórios), amplia as horas de atividades complementares de 120 horas para 300 horas e prevê maior incentivo à pesquisa e à extensão. O ponto positivo é que a maior parte dos egressos formados recentemente se consideram satisfeitos.

Gráfico 14 - Nível de satisfação em relação ao curso

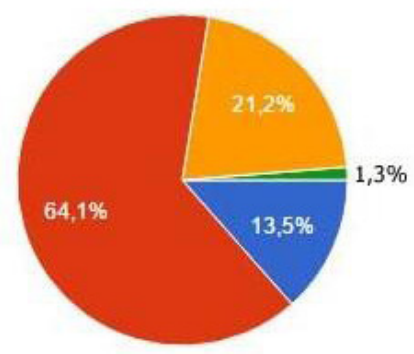

Muito satisfeito

Satisfeito

Insatisfeito

Muito insatisfeito

Fonte: Os autores (2016)

${ }^{6} 0$ nome dos entrevistados foi substituído por números a fim de preservar a identidade destes. 
A maioria dos formados estagiou (97,4\%). No entanto, quatro $(2,6 \%)$ responderam que não estagiaram (Figura 15). Isso pode ser explicado pelo fato de que o estágio só se tornou obrigatório a partir da publicação da Lei no 11.788 de 25 de setembro de 2008. Só a partir da publicação dessa lei que o estágio passou a ser pré-requisito no Projeto Político Pedagógico do curso para aprovação e obtenção do diploma.

\section{Gráfico 15 - Estágio}

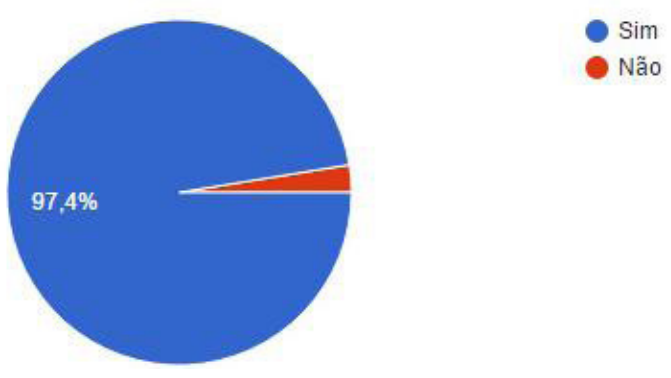

Fonte: Os autores (2016)

Aos egressos foi perguntado também qual tipo de Trabalho de Conclusão de Curso fizeram. Os trabalhos mais comuns foram: Planos de Comunicação para instituições públicas e particulares da cidade como escolas particulares, órgãos públicos, etc.; e Livro reportagem sobre temas pertinentes à cidade e região. Outros trabalhos mencionados são revistas impressas e online, jornais impressos, site de notícias e vídeo documentários. Quanto às monografias, em geral se tratam de estudo de caso, estudo comparado, análise de conteúdo e análise de discurso, basicamente de jornais e revistas locais. No entanto, alguns trataram de análises de jornais de circulação nacional como a Folha de S. Paulo. Não causa estranhamento ver a opção do plano de comunicação ser tão comum, já que a cidade tem ainda uma grande demanda reprimida nessa área de trabalho; assim como a escolha pelo livro reportagem, já que em Imperatriz são publicados muitos livros. Em 2010, já haviam 350 livros publicados pela Editora Ética - presidida na cidade, de acordo texto escrito por Franklin (2010).

Como a pergunta foi aberta, nem todos responderam a tipologia do trabalho e nem a modalidade. Foi possível saber essas informações de 119 respondentes. É importante mencionar que alguns trabalhos foram feitos individualmente e outros em dupla. Os estudos de foram separados em tipologia: monografia ou peça prática; área: impresso, webjornalismo, assessoria de comunicação, fotojornalismo, livro reportagem, etc; abrangência: regional ou nacional.

Quadro 2 - Tipologia dos TCCs

\begin{tabular}{|c|c|}
\hline MONOGRAFIA & 49 \\
\hline PEÇA PRÁTICA & 70 \\
\hline TOTAL & 119 \\
\hline
\end{tabular}

Fonte: Os autores (2016) 
Quadro 3 - Modalidades das peças práticas

\begin{tabular}{|c|c|}
\hline ASCOM & 19 \\
\hline LIVRO REPORTAGEM & 10 \\
\hline RADIO & 7 \\
\hline AUDIOVISUAL & 6 \\
\hline REVISTA & 11 \\
\hline JORNAL & 3 \\
\hline SITE DE NOTICIAS/ BLOG & 6 \\
\hline PROJETO GRAFICO & 3 \\
\hline LIVRO FOTOGRAFIA & 3 \\
\hline COLUNA/CADERNO CULTURAL & 2 \\
\hline
\end{tabular}

Fonte: Os autores (2016)

Quadro 4 - Abrangências das monografias

\begin{tabular}{|c|c|}
\hline NACIONAIS & 8 \\
\hline REGIONAIS & 41 \\
\hline
\end{tabular}

Fonte: Os autores (2016)

A partir da observação desses quadros, é possível perceber que mais da metade dos egres sos que responderam ao questionário optaram por peça prática. Também é possível verificar que a maior parte das peças práticas são livros-reportagens e produtos de Assessoria de Comunicação. Além disso, as monografias são, em sua maioria, voltadas para pautas regionais

A pergunta seguinte teve o objetivo de verificar quantos egressos estão buscando outra profissão ou apenas procurando mais capacitação. A maioria não cursou/está frequentando outro curso superior. No entanto, 25 pessoas (16\%) responderam que estão (Figura 16). Os cursos mais mencionados são Direito e Letras. Mas foram apontados também os cursos de Geografia, Pedagogia, História, Fisioterapia, Tecnologia de Gestão em Recursos Humanos e Administração, ou seja, a maioria na área de Humanas e Ciências Sociais Aplicadas.

Gráfico 16 - Formação superior posterior a Jornalismo

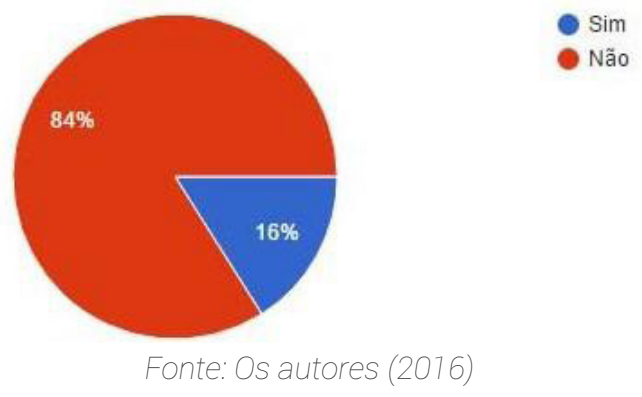

${ }^{7}$ Em anexo inclui uma lista com os Trabalhos de Conclusão de Curso (TCCs) que constam no acervo do Centro de Documentação do Jornalismo de Imperatriz. 
Além disso, considerou-se importante observar quantos fizeram ou estão fazendo pós-graduação. É possível perceber que, embora mais da metade tenha respondido "não" (62,2\%), uma parte considerável respondeu "sim" (37,8\%), como exposto na Figura 17. O fato de a maioria ainda não ter se cursado um programa de pós-graduação pode ser um bom sinal para que a universidade invista nessa área, já que há demanda.

\section{Gráfico 17 - Pós-graduação}

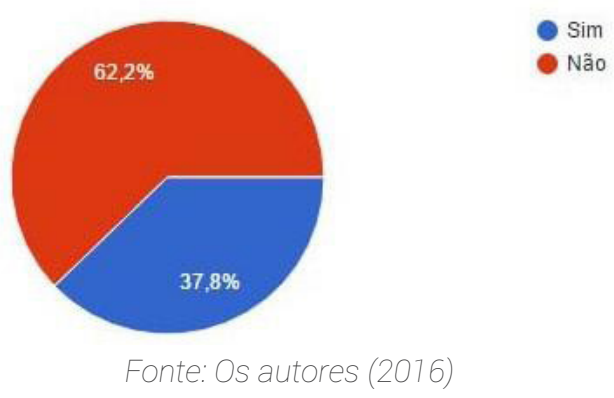

Fez-se uma análise do primeiro emprego e/ou primeiro estágio. Observou-se que 52\% iniciou sua vida profissional em Assessoria de Comunicação, mas repórter de jornal impresso e de TV também aparecem com uma porcentagem significativa, 14\% e 9\%, respectivamente. Em seguida, vem repórter de web e produção de TV com 6\% e 5\%. Repórter de revista, fotojornalista e revisor de texto também aparecem com $2 \%$ cada. Outros cargos como edição de telejornal, monitoramento de mídias, editor de site, repórter de rádio, professor, analista de TV, apresentador de telejornal, diagramador, produtor de rádio também surgem, embora com baixa porcentagem - uma pessoa em cada um dos cargos. E três dos formados informaram que nunca atuaram na área, representando 3\% da amostra. Essa informação pode significar a grande oportunidade que a área de Assessoria de Comunicação representa para os estudantes que buscam sua primeira experiência de trabalho. É uma área que tem crescido no âmbito nacional e regional. O número dos que não atuam na área também é pequeno, mostrando que o mercado tem absorvido o egresso.

Gráfico18 - Primeiro emprego

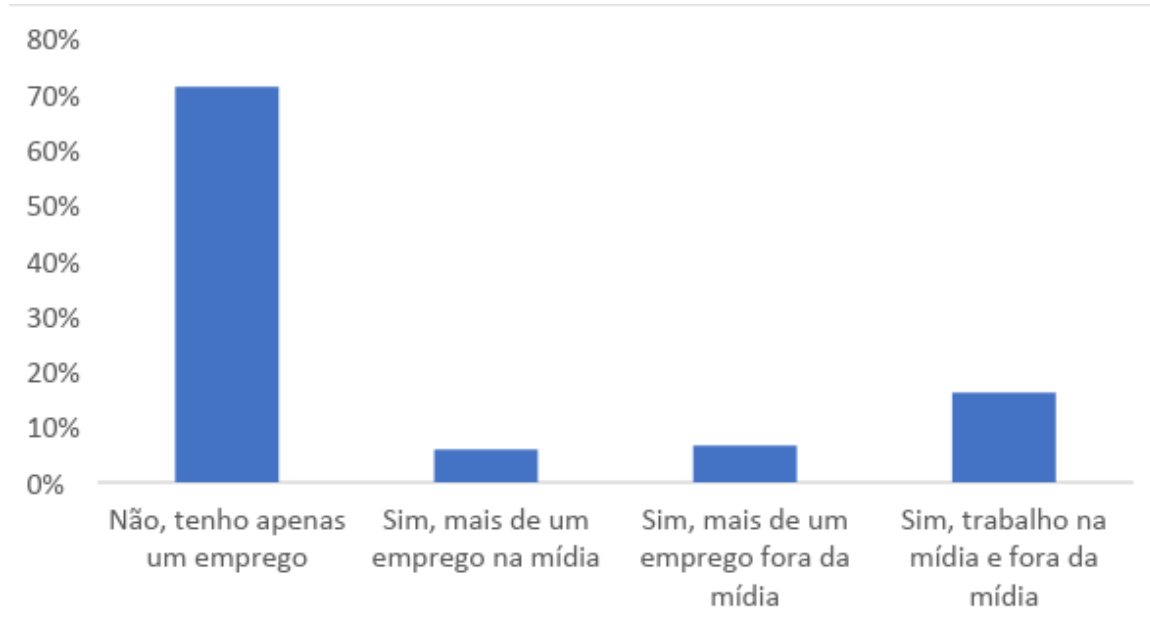

Fonte: Os autores (2016) 
A pesquisa consultou, além disso, a opinião do formado sobre a obrigatoriedade de diploma para o exercício da profissão. A maioria informou ser a favor, enquanto 1,3\% informou que só em alguns casos, e 1,3\% é contra (Figura 19). Supõe-se que quem é diplomado defenda a obrigatoriedade do diploma para o exercício da profissão, no entanto, essa discussão é muito abrangente e polêmica. Como já explicado anteriormente, é necessário levar em consideração alguns fatores como a relação empregatícia. Nesse caso, é quase unânime a opinião quanto a exigência. Entretanto, em se tratando de imprensa alternativa, jornais de bairros, sindicatos, etc. acredita-se que é preciso haver liberdade para atuar nesses meios. Isso pode explicar a existência de egressos discordarem da exigência do diploma de ensino superior para a atividade.

Gráfico 19 - Opinião sobre a exigência de diploma para atividade jornalística

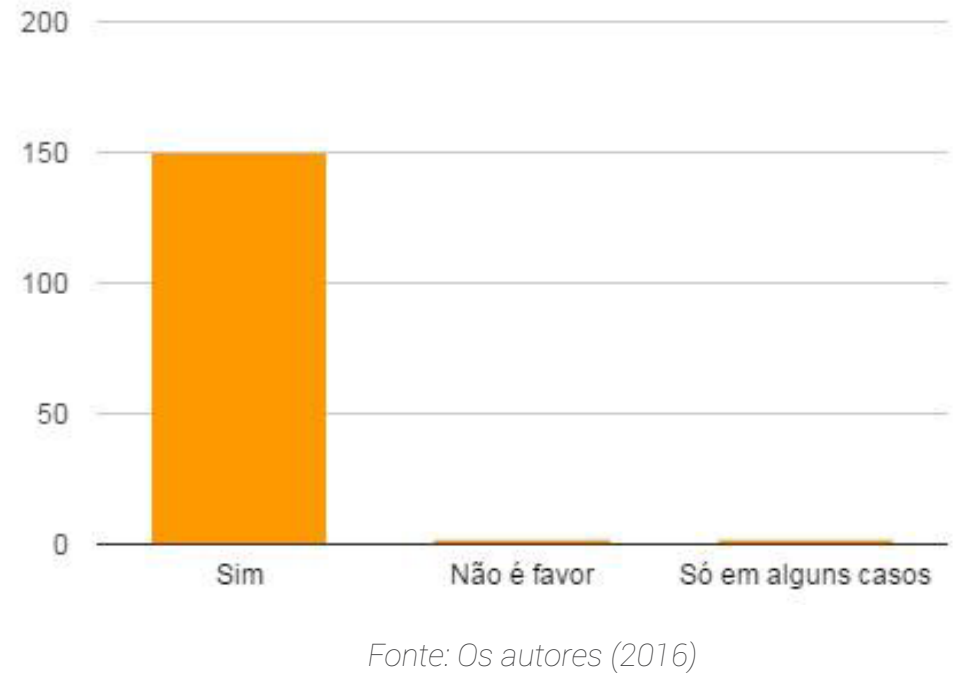

\section{Considerações Finais}

O jornalismo é uma profissão imediatista. É uma prática de relato e análise do cotidiano ancorado no presente. Está entre as máximas da profissão que "não há nada mais velho do que o jornal de ontem". Ou seja, a profissão está sempre olhando para o dia de hoje ou para o futuro. Talvez por isso tenha demorado tanto para refletir sobre o seu passado como se propôs neste levantamento: efetivamente um estudo do ocorrido. Esta pesquisa mostra que o modo como o curso de Jornalismo tem mantido contato com seu egresso ainda é falha, não é sistematizada, e depende do interesse particular de um pesquisador ou outro, quando, na verdade, deveria ser uma prática metódica da instituição. Ao analisar os resultados fica claro que a instituição só perde com isso. Mas mais que fazer uma crítica a essa postura, que de longe não foi o objetivo deste estudo, o modelo de levantamento sobre um balanço desses dez anos do curso a partir do perfil do egresso mostra que podemos aprender mais sobre o presente e sobre quem somos, adotando esse tipo de estudo.

Por essa razão, parece ser quase um ponto irrefutável na conclusão dessa análise que o perfil é uma ferramenta muito rica para enxergar a realidade e a partir dela pensar em aprofundamentos e trilhar novos ou seguir velhos caminhos. Por outro lado, ao realizar esse estudo quantitativo, observou-se que, ainda que a pesquisa quantitativa não responda todas as 
perguntas, ela abre o campo de visão para enxergar algumas questões. E embora o processo de coleta de dados seja trabalhoso, verificou-se que o maior desafio consiste, justamente, em analisar o que os dados significam. E nesse estudo eles significaram muito, permitiram compreender melhor a própria formação em Jornalismo sob o olhar dos ex-alunos.

Assim, contribuição desejada é que o levantamento aqui estabelecido possa favorecer discussões para a elaboração de uma nova grande curricular capaz de equacionar questões ainda defasadas no curso analisado. Repensar, por exemplo, a relação de formados frente ao número de entrantes no curso e as motivações de atrasos/desistências desses durante a graduação, os pontos indicados que fundamentam as insatisfações sobre o processo de graduação, as opções de cursos de pós-graduação na região diante do perfil dos graduados, entre tantos outros temas, parece ser o caminho para promoção de ajustes nos processos educacionais e estratégicos do curso de Jornalismo de Imperatriz para os próximos anos.

Por fim, é preciso ponderar que essa pesquisa não pretende responder a todas as questões relacionadas ao universo dos formados. Antes, porém, almeja-se servir de ponto de partida para futuras investigações, pois acredita-se que há espaço para outras interrogações, como por exemplo, explorar questões relacionadas ao comportamento dos estudantes e/ou egressos do curso quanto ao hábito de leitura ou a questões relacionadas a religião ou temas como sexualidade. Outrossim, até aqui, acredita-se ter dado um passo inicial para refletir que tipo de curso de Jornalismo a UFMA oferece e que tipo de aluno a universidade tem formado.

\section{Referências}

BIBLIOTECAS PÚBLICAS MUNICIPAIS DE GUARULHOS BIBLIOTECA CENTRAL MONTEIRO LOBATO. Disponível em: <http://www.bibliotecaguarulhos.com.br/p/sobre.html>. Acesso em: 6 de ago. 2016.

DIRETRIZES Curriculares Nacionais para o Curso de Jornalismo. Relatório da Comissão de Especialistas instituída pelo Ministério da Educação, 2013. Disponível em: <http://portal.mec. gov.br/dmdocuments/documento_final_cursos_jornalismo.pdf>. Acesso em: 7 jun. 2016.

FENAJ,Formação Superior em Jornalismo: uma exigência que interessa à sociedade / Federação Nacional dos Jornalistas, organização - Florianópolis, 2002, 2ª edição.

FENAJ,Pesquisa "Perfil profissional do jornalismobrasileiro - Etapa 1.

FOLHA DE SÃO PAULO. Ranking universitário folha 2014, Jornalismo.Disponível em: <http:// ruf.folha.uol.com.br/2014/rankingdecursos/jornalismo/>. Acesso em: 7 de ago. 2016.

HIME, Gisely Valentim Vaz Coelho. Na Fundação da Primeira Escola de Jornalismo do Brasil: Cásper Líbero gera o conceito de Jornalismo Moderno. Florianópolis, 2004. Disponível em http://www2.eca.usp.br/pjbr/arquivos/artigos3_b.htm. Acesso em: 13 de jul de 2016.

IBGE-Instituto Brasileiro de Geografia e Estatística. Maranhão >> Imperatriz. Disponível em: <http://cidades.ibge.gov.br/xtras/perfil.php?codmun=210530>. Acesso em: 08 de jan. 2017. 
craradoreso

KOTSCHO, Ricardo. Ombudsman da Folha defende a autorregulação da imprensa. Revista Brasileiros.

MELO, José Marques de. A natureza do jornalismo e a missão do jornalista segundo Costa Rego. Manaus, 2010. Disponível em: <http://www.portcom.intercom.org.br/pdfs/24c0adbd2ecb31b4737709c8dac85350.pdf>. Acesso em: 12 jul 2016.

Recebido: 20/77/2018

Aceito:07/05/2019 